\title{
Salter osteotomisi
}

\author{
Salter Osteotomy
}

Haluk Ağuş

Tepecik Eğitim ve Araştırma Hastanesi, Ortopedi ve Travmatoloji Kliniği, İzmir

Salter osteotomisi, 2-9 yaşları arasında, gelişimsel kalça displazisi tanısı konmuş olgularda uygulanan, etkin bir cerrahi tedavi yöntemidir. Yöntemin gerekliliklerine ve tekniğine uyum başarı oranını arttırır. Bu osteotomi, asetabulumun konumunu değiştirerek anterolateral asetabular yetmezliğin giderilmesini sağlar.Yetersiz asetabular gelişme, femur başının avasküler nekrozu ile erken veya geç dönemde görülen tekrarlayan çıkıklar, başlıca komplikasyonlarıdır.

Anahtar sözcükler: gelişimsel kalça displazisi; pelvik ostetomi; Salter

\begin{abstract}
Salter innominate osteotomy is an effective treatment method for the developmental dyspalsia of hip which is diagnosed between 2-9 years of age. Correct application of its technical principles and prerequisites are important factors for successful results. Anterolateral acetabular deficiency of the acetabulum is treated by changing the position of acetabulum as a result of this osteotomy. Insufficent acetabular development, avascular necrosis of femoral head, early or late redislocation are the main complications.
\end{abstract}

Key words: developemental hip dysplasia; pelvic ostetomy; Salter
B ir eklemin gelişiminde ve işlevinde, eklem yüzlerinin uyumlu olması ile hareket genişliğinin tam olması en önemli unsurlardandır. Bu nedenle, kalça ekleminde ortaya çıkan femur başının örtünme yetersizliği, bebeklik çağlarında kalça ekleminin gelişimini olumsuz olarak etkiler ve daha ileri yaşlarda değişen biyomekanik koşullar nedeniyle erken dejeneratif değişikliklere yol açar.

Uygun olmayan femur başı asetabulum ilişkisinin saptandığı durumlarda amaç, femur başı ile asetabulum arasında uyumlu bir bütünlük elde ederek kalça ekleminin normal fizyolojik gelişimini sağlamak olmalıdır. Bununla birlikte, bu sorun kalça gelişim potansiyelinin azalmaya başladığı veya olmadığı yaşlarda saptanırsa, çeşitli cerrahi girişimlerle, uygun baş asetabulum ilişkisi yaratılmaya çalışılır. Pelvik osteotomiler bu tür girişimlerin önemli bir bölümünü oluşturur.

Salter osteotomisi, özellikle anterolateral yetmezliği olan gelişimsel kalça displazili (GKD) olgularda, asetabulumun öne ve yana doğru yer değiştirmesine olanak sağlayarak femur başının örtülme oranını arttırmayı amaçlayan bir pelvik ostetomidir. Kanadalı ortopedi cerrahı olan Robert B. Salter tarafindan tanımlanmıştır. ${ }^{[1]}$

\section{SALTER OSTEOTOMISININ GEREKLILIKLERI}

Salter osteotomisinin en önemli gerekliliği, kalçanın konsantrik olarak redükte edilebilmesidir. Osteotomi sonunda kalça konsantrik olarak redükte durumda tutulamıyorsa, cerrah redüksiyonu engelleyen nedenleri değerlendirip düzeltmelidir. ${ }^{[2,3]}$ Redüksiyonu engelleyen unsurların başında, osteotomiden sonra, kalça çevresinde oluşan kas gerginliği gelir. Distal osteotomi parçasının öne ve yana doğru yer değiştirmesi ile, iliopsoas ve adduktor kaslar gergin hale gelir. Bu durum, kalça eklemine aşırı kuvvet uygulayarak, kalçanın redükte olmasını engelleyebilir ve sekonder çıkıklara neden olabilir. Bu nedenle, ostetomi ile birlikte adduktor ve iliopsoas kaslarının tenotomisi uygulanmalıdır. Tenotomilerden sonra, konsantrik redüksiyon

- İletişim adresi: Dr. Haluk Ağuş, Tepecik Eğitim Hastanesi, Ortopedi Kliniği Yenişehir, İzmir

Tel: 532 - 2445087 e-posta: halukagus@yahoo.com

- Geliș tarihi: 23 Ocak 2015 Kabul tarihi: 23 Ocak 2015 
sağlanamıyorsa açık redüksiyon yapılmalıdır. Açık redüksiyon sırasında eklem kapsülünün anterior ve inferiorunun gevşetilmesi, transvers bağın kesilmesi ve ligamentum teresin çıkarılması, konsantrik redüksiyonun sağlanabilmesi için göz önünde tutulması gereken aşamalardır. İleri yaşlarda ve femur başının yüksekte olduğu GKD'li olgularda yapılan tenotomiler, kalça ekleminin kolayca redükte olabilmesi için gerekli gevşemeyi sağlayamayabilir. Bu gibi durumlarda, femura kısaltma ameliyatı uygulanarak kalça çevresindeki kaslarda istenen gevşeme elde edilir. ${ }^{[4,5,6]}$

Salter osteotomisinin diğer bir gerekliliği, uygulanacağı yaş aralığının doğru saptanmasıdır. Bu osteotomi, 2-9 yaş grubuna uygulanır. On sekiz aylıktan küçük çocukların, iliak kanatları kemik greftine destek olacak kalınlıkta değildir. Yaşları 9-10 arasındaki çocuklarda ise, asetabulumu femur başını örtecek derecede devirmek güçtür ve gerekli femur başı örtünmesi sağlayabilmek için, daha karmaşık osteotomilere ihtiyaç duyulur.

\section{Cerrahi teknik}

Cerrahi yaklaşım, ameliyatın tüm aşamalarının tek kesiden yapılmasına olanak sağlayacak şekilde olmalıdır. Hasta sırtüstü yatırılır; açık redüksiyon ve osteotomi yapılacaksa, genellikle iliak kanadın ortasından başlayarak, spina iliaka anterior superiorun distaline kadar uzanan bir kesi tercih edilir. Bazı yazarlar, bu kesinin aşırı nedbe dokusuna neden olduğunu belirtip, trokanter majörle iliak kanat arasındaki mesafenin 3/2 üst bölümünden başlayıp, spina iliaka anterior inferiorun bir miktar mediyaline uzanan 'bikini' insizyonunu önermektedirler. ${ }^{[7]}$ Katlar geçildikten sonra, iliak apofiz iki taraflı olarak kalça kapsülünün üst kısmına ve her iki taraftaki siyatik çentiğe ulaşılana kadar sıyrılır. Ardından, rektus femoris, spina iliaka anterior inferiordan askıya alınarak ayrılır. Eklem kapsülünün ön ve yan kısımları açığa çıkarıldıktan sonra, kapsül asetabulumun ön kenarına paralel olacak şekilde açılır. Kapsül kesisinin üst kısmında laterale doğru ek bir kesi daha yapılıp, femur başı asetabulumun içini görecek şekilde laterale çıkarılır. Ligamentum teres, ilk önce femur başına yapıştığı yerden kesilir, ardından pensle tutularak kapsülün ön kısmının açılmasında asetabuluma yapışma yerine doğru kapsülün ön kısmı açılır. Ligamentum teres, asetabuluma yapıştı̆̆ı yerden de kesilerek çıkarilır. Daha sonra, inferior kapsül ve transvers bağ kesilerek, eklemde redüksiyonu engelleyecek unsurlar gevşetilir.

Osteotomi aşamasında, iliak kanadın iki yanındaki yumuşak dokular ekarte edilirirken, ucu $90^{\circ}$ kıvrık olan pens, periost altında kalmaya dikkat edilirken siyatik çentiğe dışarıdan içeriye doğru geçirilir. Gigli testeresi, mediyalde pensle tutulup lateralden çıkarılır. Testere yardımı ile, siyatik çentikle spina iliaka anterior inferior arası osteotomize edilir. Osteotomi sırasında, lateraldeki testere kısmının mediyaldekine göre daha superiorda olmasına dikkat edilmelidir. Bu menevra, iliak kanat devrildikten sonra osteotomi hatlarının greft stabilizasyonunda daha etkili olacak şekilde kesilmesini sağlar. iliak kanadın superiorundan, tabanı superior ve inferior iliak çıkıntılar arası kadar olacak şekilde üçgen greft alınır. Osteotominin proksimalindeki iliak kanat bir çamaşır pensi ile sabitlenirken, distal osteotomi parçası çamaşır pensi veya pübik kol üzerine takılan ucu eğri pensle aşağı, öne ve yana doğru çekilir. Açılan osteotomi hattına greft yerleştirildikten sonra, greft iliak kanadın kenarından asetabulumun arkasına doğru yöneltilmiş K-teli ile tutturulur. Açık redüksiyon yapılmışsa, K-telinin eklem içinde olup olmadığı parmakla kontrol edilmelidir. K-telinin ucu deri altı yağ dokusunun içinde kalacak şekilde kesilerek, ilak apofiz ve cilt kapatılır. Kalça hafif abduksiyon ve iç rotasyon, diz ise $20^{\circ}$ fleksiyonda olacak şekilde, karşı taraf diz üstüne kadar pelvi pedal alçı uygulanır. Genellikle altı hafta sonunda, kaynama oluştuktan sonra alçı çıkarılarak serbest hareketlere izin verilir. Bir ila iki hafta sonra, koltuk değnekleri ile kısmi yük taşınmasına, daha sonra da tam yüklenmeye geçilir.

\section{SALTER OSTEOTOMISINI YAPARKEN DIKKAT EDILECEK HUSUSLAR}

Salter osteotomisinin başarılı olmasında, uygulamadaki teknik ayrıntılara dikkat edilmesinin önemli etkisi vardır. Osteotomi sırasında periost altında kalınması, siyatik sinir yaralanmasını engeller. illiopsoas tenotomisi yapılırken veya distal parçanın aşırı derecede çekilmesi ile, femoral sinir hasarının oluşabileceği akılda tutulmalıdır. Ostetomi hattını ve grefti tespit ederken, K-tellerinin biri asetabulum arkasına diğeri ise ekleme girmeyecek şekilde asetabulumun üstünden yerleştirilmeli ve konumları radyolojik olarak görülmelidir. Açık redüksiyon yapılmışsa, K-tellerinin ekleme girip girmedikleri parmak ucu ile kontrol edilmelidir.

Asetabulum yeni konumuna getirilirken, osteotomi hattının arka köşesinin açılması önerilmez. Açıldığı takdirde asetabuluma uygun konum verilemiyeceği ve bacakta uzamaya neden olacağı belirtilir. Bununla birlikte, osteotomi hattının açılması ve trapezoid greft kullanarak uygun asetabular konumlamanın sağlanmasının yanında, özellikle femoral kısaltmanın yapıldığı olgularda, transiliak uzatma oluşturularak ekstremite uzunluk eşitliğinin sağlandığı osteotomi modifikasyonları da vardır. ${ }^{[8]}$ 
Distal parçanın mediyalize olması, genellikle yetersiz tespit neticesinde oluşur. Bu sorunla karşılaşmamak için, K-telleri ile tutturulduktan sonra, greft stabilitesi bir pensle tutulup çekilerek değerlendirilmelidir. Yetersiz tespit, greftin konumunu kaybetmesi ile de sonlanabilir. Osteotomi 18 aylıktan küçük çocuklara uygulandığı takdirde, iliak kanatlar ince olduğundan, greftin ve osteotomi hattının tespit sorunları ile karşılaşmak olasıdır. ${ }^{[9]}$

Salter ostoetomisi ile asetabular indekste ortalama $10^{\circ}$ 'lik bir düzelme beklenir. Bununla birlikte, modifiye tekniklerle $20^{\circ}$ 'ye kadar düzelme sağlanabildiği gösterilmişse de, aşırı düzeltmenin asetabulumun arkasında defekt yaratabileceği ve ön tarafta da sıkışmaya yol açabileceği belirtilmektedir. íki taraflı GKD'li olgularda, aynı seansta yapılacak iki taraflı osteotomide pelvik dengesizlik yaratılarak, gerekli asetabular düzelmenin sağlanamayacağı öne sürülmektedir. Bu olgularda, osteotomilerin en az iki hafta ara ile uygulanması gerektiği belirtilmekte ise de, eş zamanlı yapılan osteotomiler ile gerekli asetabular düzelmenin elde edilebildiğini gösteren araştırmalar vardır. ${ }^{[10]}$

\section{SALTER OSTETOMISININ KOMPLIKASYONLARI}

Salter osteotomisinin erken komplikasyonları, çıkık ve konsantrik redüksiyonun sağlanamamasıdır.

Her iki komplikasyonun nedeni de, genellikle yumuşak dokulardaki aşırı gerginlik veya yetersiz yumuşak doku gevşetilmesidir. Bu nedenle, yarı çıkık kalçalarda yeterli adduktor ve iliopsoas tenotomileri yapılmalıdır. Tam çıkık kalçalarda ise, traksiyon yapılmaksızın uygulanan femoral kısaltma, açık redüksiyon, inferior kapsülün gevşetilmesi, adduktor ve iliopsoas tentomisi, bir de transvers bağın kesilmesi ile yeterli yumuşak doku gevşemesinin sağlanıp tam uyumlu konsantrik bir redüksiyon sağlamak mümkün olmaktadır. Femoral kısaltma ve derotasyon osteotomisi uygulanan olgularda, derotasyon hataları ve yetersiz kısaltma erken çıkık nedeni olabilir. Femoral kısaltma miktarı, intertrokanterik osteotomi yapılıp femur başı redükte edildikten sonra osteotomi hattında üst üste binen diyafiz miktarı kadar olmalıdır. Redüksiyon sağlandıktan sonra, ameliyat sırasında kalçaya aşırı bir pozisyon vermeden yaptırılacak $80-90^{\circ}$ 'lik fleksiyon sırasında kalçanın çıkmaması, stabil bir redüksiyon elde edildiğini gösterir. Bu test sırasında kolayca çıkık oluyorsa, yeterli gevşetmenin yapılıp yapılmadığı veya femoral versiyon kusurları kontrol edilmelidir.

Salter osteotomisi uygulanan olgularda, geç dönemde ilerleyici çıkık, femur başı avasküler nekrozu ve eklem sertliği gibi sorunlarla karşılaşmak olasıdır. ilerleyici çıkık asetebulumun yetersiz devrilmesi, aşırı femoral anteversiyon, yetersiz yumuşak doku gevşetmesi ile kapsül gevşekliği sonrasında gelişebilir. Osteotomiden sonra oluşan aşırı yumuşak doku gerginliği, aşırı yumuşak doku sıyrılması ve redüksiyonu sağlamak için kalça eklemine verilen aşıı pozisyonlar, femur başının avasküler nekrozuna yol açabilir. Ayrıca, dört yaşından sonra yapılan girişimlerde, femur başı avasküler nekrozu görülme olasılığı artar. Eklem sertligi ise, yetersiz gevşetme ile eklemi gergin bir şekilde redükte etme, aşırı yumuşak doku gevşetmesi yaptıktan sonra uzun süreli tespit etme veya K-tellerinin eklem kıkırdağını rahatsız etmesine bağlı oluşan kondroliz sonucunda görülür.

Salter osteotomisi yapılan olgularda, prognozu etkileyebilecek iliak devrilme oranı, femur başının lateralizasyonu, femur osteotomisinin niteliği gibi radyolojik unsurların değerlendirilmesi önemlidir (Şekil 1). Ayrıca, erken dönemde sağlanan santralizasyon ve femur üst ucunun uygun olarak düzeltilmesi başta olmak üzere, çıkık kalça çevresindeki tüm patolojilerdeki düzelme miktarı ve oluşturulan uyumluluk, tedavinin prognozunu göstermesi açısından önemlidir. Bununla birlikte, radyolojik değerlendirmelerin, prognozda etkili olan yumuşak dokuların etkisini belirtmediği göz önünde tutulmalıdır. ${ }^{[11]}$

GKD'li olgularda, Salter osteotomisi ameliyatından önce asetabulumun konumu ve mevcut patoloji ayrıntılı olarak değerlendirilmelidir. Salter osteotomisi, asetabulumun şekil ve hacmini değiştirmeden, simfiz pubisin menteşe olarak kullanılıp konumunu değiştirilmesi esasına dayanır ve bu nedenle, yönlendirici osteotomi olarak tanımlanır. Asetabulumun, özellikle ön kenarındaki yetmezliğinin tedavisinde ve bir dereceye kadar lateral yetmezliğinin giderilmesinde kullanılır. Asetabulumun arkasında bir yetmezlik saptanırsa, Salter osteotomisi bu patolojiyi daha da arttıracağından, bu olgular Pemberton veya Dega tipi osteotomilerle düzeltilmelidir.

\section{SALTER OSTEOTOMISININ SONUÇLARI}

Salter osteotomisinin sonuçları değerlendirildiğinde, matüriteye kadar olan izlemlerde endikasyon ve teknik ayrıntılara uyulduğu takdirde başarılı sonuçlar elde edilmekle birlikte, özellikle dört yaş altında ameliyat edilen olgularda daha başarılı sonuçlar sağlandığı bildirilmektedir (Şekil 2). Salter ve Dubos, ortalama 5,5 yıl izledikleri olgularında çok iyi sonuç oranını, dört yaş altında ameliyat ettikleri hastalarda \%93,6 olarak bildirmişlerdir. Yazarlar, bu oranı beş yaşının 


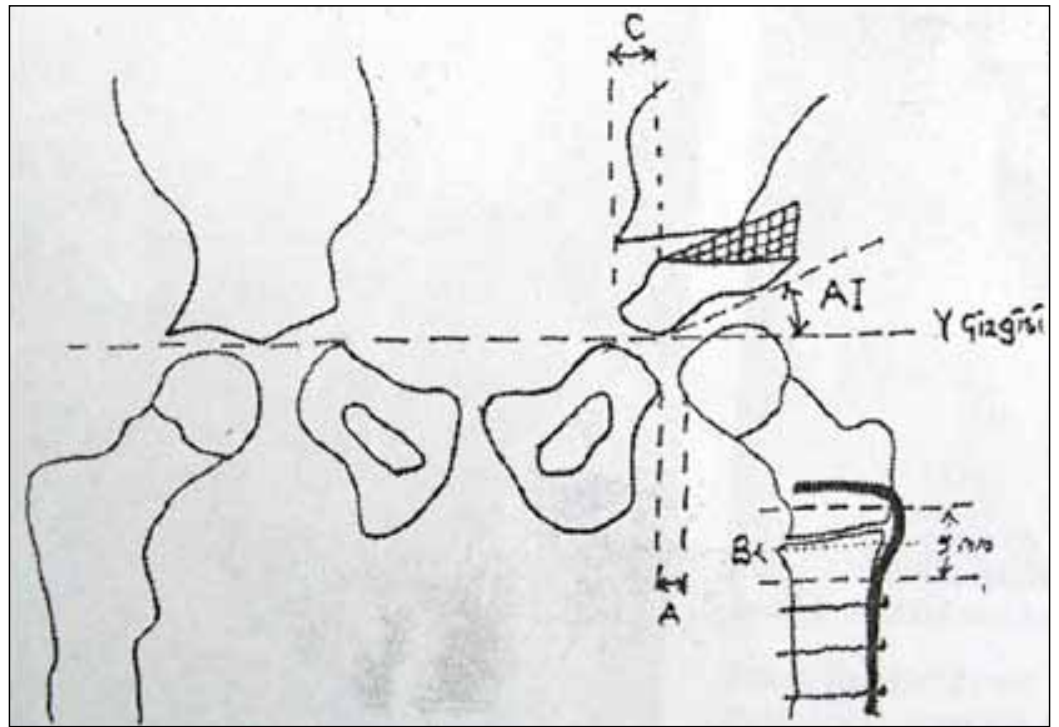

Şekil 1. Kombine girişim uygulanan olguların değerlendirme kriterleri. A: Femur başı ile iskiumun dış kenarı arasındaki mesafe $(5 \mathrm{~mm}$ üzerindeki değerler subluksasyon belirtisidir). B: Femur osteotomisi trokanter minor merkez olacak şekilde $5 \mathrm{~mm}$ 'lik bir alanda yapılmalıdır. C: Salter osteotomisi sonucu, parça nötral veya mediyal konumda olmamalıdır. Al: Asetabular indeks, Salter osteotomisi neticesinde azalmalıdır.
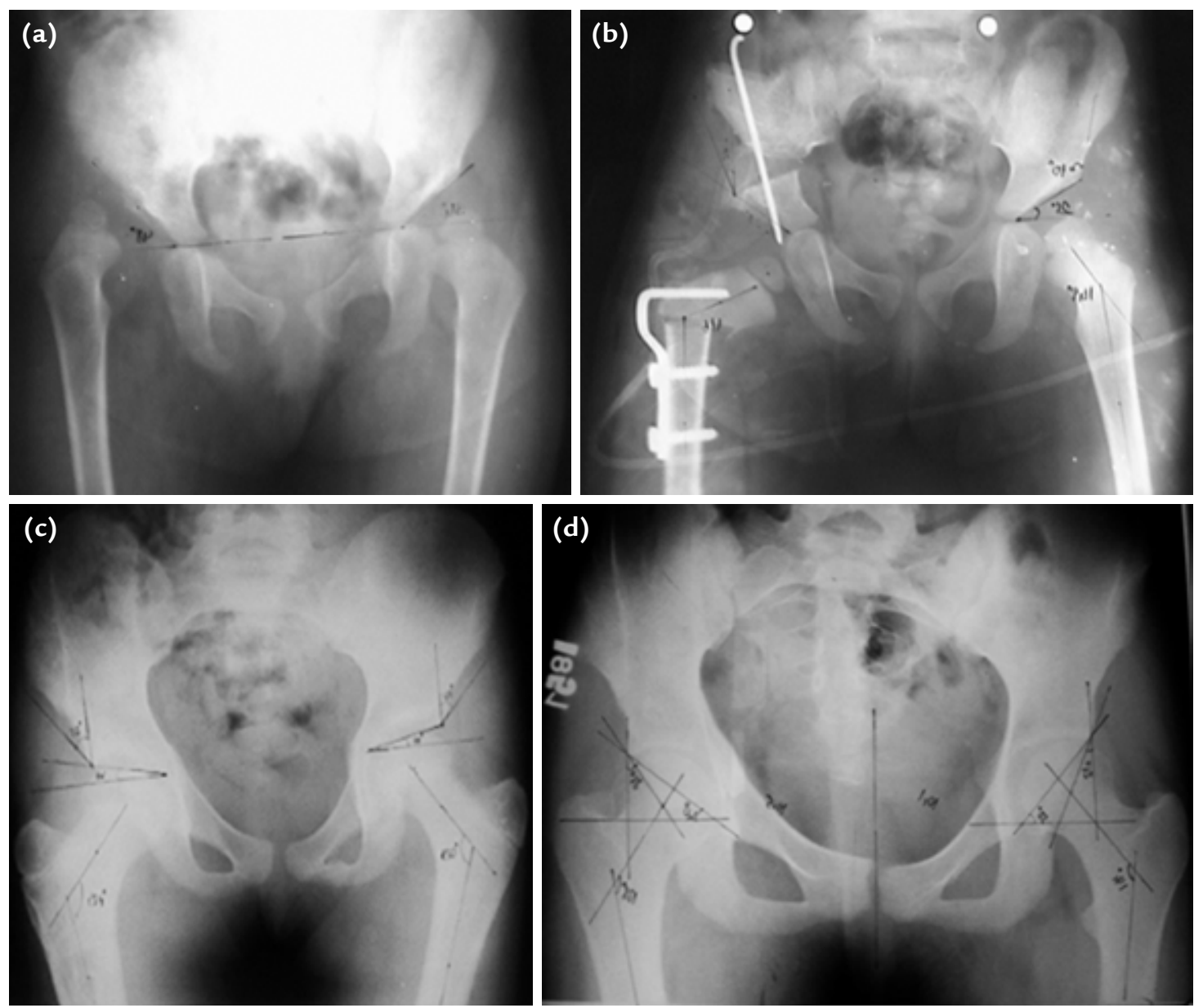

Şekil 2. a-d. Kombine ameliyat uygulanan olgu. Ameliyat öncesi (a); ameliyat sonrası (b); ameliyat sonrası 7 yıl (c); ameliyat sonrası 12 yıl 6 ay (d). 
üzerindeki olgularda \%56,7 olarak vermektedirler. ${ }^{[2]}$ Gulman ve arkadaşları ise, Salter osteotomisi ve açık redüksiyonla tedavi edip ortalama 13 yıl izledikleri olgularda başarılı sonuç oranlarının, dört yaşından önce ameliyat ettikleri olgularda daha yüksek olduğunu belirtmişlerdir. ${ }^{[12]}$ Bununla birlikte, Salter osteotomisinin uzun süreli sonuçları değerlendirildiğinde, Thomas ve arkadaşları, 2-9 yaş arasında Salter osteotomisi uygulanan 80 kalçanın 45 yıl sonunda $\% 45$ 'inde gelişen osteoartrit neticesinde, total kalça protezi uygulandığını saptamışlardır. Araştırıcılar, iki taraflı olgularla, ameliyat sonunda gelişen komplikasyonların prognozu kötü etkileyen tehlike unsurları olduğunu belirtmektedirler.[13]

\section{ÇIKARIMLAR}

Salter osteotomisi, özellikle geç tanı konmuş GKD'li olguların tedavisinde uygulanan başarılı bir cerrahi yöntemdir. Başarılı sonuç elde etmede, girişimin teknik ayrıntılarının ve gerekliliklerinin uygulanması esastır. Bu yöntemle tedavi edilen olgularda ergenliğe ulaşana kadar elde edilen yüksek başarı oranları, özellikle 40'lı yaşlardan sonra düşme eğilimine girmektedir.

\section{KAYNAKLAR}

1. Salter RB. The classic. Innominate osteotomy in the treatment congenital dislocation and subluxation of the hip by Robert B. Salter, J. Bone Joint Surg. (Brit) 43B:3:518, 1961. Clin Orthop Relat Res 1978;(137):2-14.

2. Salter RB, Dubos JP. The first fifteen year's personal experience with innominate osteotomy in the treatment of congenital dislocation and subluxation of the hip. Clin Orthop Relat Res 1974;(98):72-103.
3. Herring JA. Salter Innominate Osteotomy. In: Herring JA, editor. Tachdjian's Pediatric Orthopaedics, 5th ed. Philadelphia, PA: Elsevier Saunders; 2014. p.525-8.

4. Ağuş $H$, Araç Ş, Us MR, Erdem EL, Açarı MA. Doğuştan kalça çıkığının tedavisinde femoral osteotomi ve traksiyonun etkilerinin karşılaştırılması. Acta Orthop Traumatol Turc 1987;21:159-62.

5. Klisic $P$, Jankovic L, Basara $\mathrm{V}$. Long term results of combined operative reduction of the hip in older children. J Pediatr Orthop 1988;8(5):532-4.

6. Karakaş ES, Baktir A, Argün M, Türk CY. One stage treatment of congenştal dislocation of the hip in older children. J Pediatr Orthop 1995;15(3):330-6.

7. Herring JA. Salter Innominate Osteotomy. In: Herring JA, editor. Tachdjian's Pediatric Orthopaedics, 5th ed. Philadelphia, PA: Elsevier Saunders; 2014. p.575-9.

8. Millis MB, Hall JE. Transiliac lengthening of the lower extremity. A modified innominate osteotomy for the treatment of the postural imbalance. J Bone Joint Surg Am 1979;61(8):1182-94.

9. Pekmezci M, Yazici M. Salter osteotomy: an overview. Acta Orthop Traumatol Turc 2007;41 Suppl 1:37-46.

10. Agus H, Bozoglan M, Kalenderer Ö, Kazımoğlu C, Onvural B, Akan i. How are outcomes affected by performing a one-stage combined procedure simultaneously in bilateral developmental hip dysplasia? Int Orthop 2014;38(6):121924. CrossRef

11. Ağuş H, Kalenderer Ö, Pedükcoşkun S, Eryanılmaz G, Reisoğlu A. Yürüme sonrası gelişimsel kalça çıkığının tedavisinde erken prognostik faktörlerin değerlendirilmesi. Acta Orthop Traumatol Turc 1999;33:35-9.

12. Gulman B, Tuncay IC, Dabak N, Karaismailoglu N. Salter's innominate osteotomy in the treatment of congenital hip dislocation: a long term review. J Pediatr Orthop 1994;14(5):662-6.

13. Thomas SR, Wedge JH, Salter RB. Outcome at forty-five years after open reduction and innominate osteotomy for latepresenting developmental dislocation of the hip. J Bone Joint Surg Am 2007;89(11);2341-50. 